\title{
Intelligent Face Tracking for Collaborative Synchronous e-Learning using Pattern Recognition Model
}

\author{
Kittimasak Naijit \\ Department of Multimedia Technology \\ Faculty of Science, Chandrakasem Rajabhat University \\ Bangkok, Thailand \\ kittimasak@yahoo.com
}

Received: April 25, 2019. Revised: June 18, 2021. Accepted: October 19, 2021. Published: November 24, 2021.

\begin{abstract}
Intelligent Face Tracking for Collaborative Synchronous e-Learning using Pattern Recognition Model can provide high levels of interaction for distance learning initiatives. With the rapid evolution of technology, face recognition login and tracking, continuous product evaluation is necessary to ensure optimal methods and resources for connecting students, instructors, and educational content in rich, online learning communities. This article presents the analysis of online, synchronous learning solutions. Focusing on their abilities to meet technical and pedagogical needs in higher education. To make a solid comparison, the systems were examined in online classrooms with instructors, guest speakers, and students. Relative to usability, instructional needs, technical aspects and compatibility are outlined for systems.
\end{abstract}

Keywords - e-learning; distance learning; collaborative learning; pattern recognition; face recognition tracking.

\section{INTRODUCTION}

In a relatively short amount of time, e-Learning has gained a permanent, highly visible place in the worldwide higher education community. A practice that a few years ago held only a niche role now is an indispensable element of many institutions' curricula, success, and overall reputation. From working adult learners to full-time students living on and off campus to dedicated educators, individuals are increasingly taking advantage of synchronous e-Learning opportunities such as virtual lectures and mentoring, as well as asynchronous e-Learning offerings such as digital online courses, flexible content creation and distribution, and builtin assessment tools.

Collaborative synchronous e-learning is live, real-time and usually scheduled, facilitated instruction and learningoriented interaction. This research emphasized "learningoriented interaction" in order to differentiate synchronous learning from lecture, product demonstrations, and other "knowledge dispersal" activities. In opinion backed by plenty of research findings, the interaction is essential to learning. Collaborative synchronous e-Learning is synchronous learning that takes place through electronic means. Synchronous learning is distinguished from self- paced asynchronous learning, which students access intermittently on demand. Synchronous e-Learning has grown rapidly to become a significant component in most organizations and training environments. Collaborative synchronous e-Learning is live, real-time, interactive, electronically-enabled learning. Synchronous e-Learning sessions can usually be recorded and played back, but that's not their primary strength or purpose. This research focus is on the live and the collaborative.

Although synchronous e-Learning is about utilizing tools to achieve effective training and education, identifying the main categories of synchronous e-Learning technologies is a good place to begin. Even though the rest of this research deals with what we will refer to as the "Web conferencing" category, it is important to differentiate these terms: Teleconferencing and its major sub-categories, audioconferencing and videoconferencing; Webcasting; Simulations; and Web conferencing.

\section{KEY AdVANTAGES TO USING}

Like most successful technology areas, synchronous e-Learning emerged to fill a need and then expanded to provide options previously unavailable to early adopters. The roots of synchronous e-Learning derive from three main influences: the classroom, the media, and the conference.

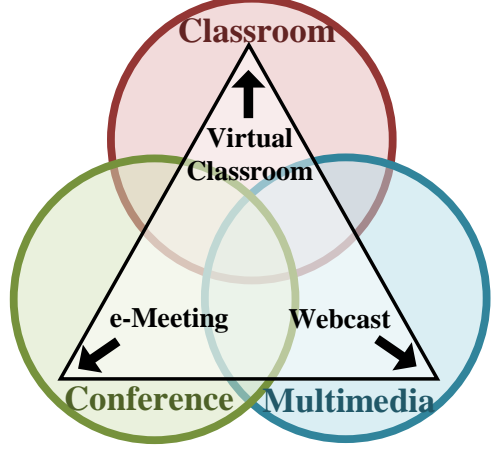

Figure 1. Intelligent Face Tracking for Collaborative Synchronous e-Learning has roots in the classroom, online comferening, and mass multimedia formats. 
There are plenty of great reasons to adopt synchronous e-Learning approaches. Determining whether a learning need for synchronous e-Learning exists is rooted in its core definers. Synchronous e-Learning is real-time, interactive, collaborative and participatory, versatile, multi-modal (combining text, audio, video, graphics, etc.), and most importantly, fun and effective. Some of the key advantages to using Collaborative synchronous e-Learning include:

\section{A. Connecting dispersed learners}

Synchronous methods are especially well suited to organizations with geographically distributed learning populations. For instance, you may have a nationwide audience of regional representatives who need updating on product features and enhancements. Firms with telecommuters and remote learners will also realize tremendous advantages.

\section{B. Real-time interaction and collaboration}

Synchronous tools allow us to engage with other audience in real time, a very natural process that permits a spontaneous and flowing learning session. Answers to questions are immediate and clarification can be provided directly. Synchronous tools also lend themselves well to structured collaborative assignments. The social dimension of synchronous tools creates a learning synergy.

\section{Sense of immediacy and co-presence}

Synchronous tools are ideal for conveying late-breaking and time sensitive information. Since the human presence is so "front and center" when using these tools, the warm learner experience that is generated allays anxieties about the mechanical or depersonalized nature of technologyenabled learning.

\section{Fostering a learning community}

Learners benefit from sharing ideas and experiences with their colleagues. A major advantage to synchronous eLearning tools is the development of a sense of connectedness and community among learners. Long term impacts can include better teamwork and collaboration skills, improved employee retention, stronger morale, and the formation of a collective identity.

\section{E. Balancing learning dynamics}

Synchronous e-Learning can reduce imbalances and create a more egalitarian learning experience. It can avoid the power dynamics of the face-to-face learning environment, where extroverts can dominate and where gender and other personal identifiers can impact group activities. Used effectively, synchronous e-Learning tools can overcome some of those barriers and level the field. The use of anonymous feedback tools can increase the comfort level of online participants by reducing the fears that adult learners often have around answering incorrectly in front of their peers. More generally, the variety of tools and communication choices available in synchronous e-Learning provides numerous options for connecting with diverse learners with different learning styles.

\section{F. Unique functionality}

Many synchronous e-Learning tools include features and functionality that offer unparalleled opportunities for fast and effective learning. Whiteboarding tools can permit class exercises that can be easily saved and recalled. Application sharing allows for rapid and easy group work. Web tours can guide learners to specific points of interest.

\section{G. Extending application demonstrations}

Provide software and desktop learning can benefit tremendously from the real-time application demonstration features of synchronous tools. Many tools also provide integrated virtual lab components, permitting supervised simultaneous practice sessions

\section{H. Synthesizing materials and concepts}

Process-oriented tasks and information-heavy materials are best taught through asynchronous, on-demand training or reference materials. But the collaborative nature of synchronous tools makes them well suited to permitting learners to synthesize complex ideas. Synchronous eLearning provides an online means for group learning techniques through discussions and dialogue, problemsolving exercises, and thoughtful reflection.

\section{MAKING THE CONNECTION}

Unlike basic audio conference calls, conferencing tools that support effective instructional methods to appeal to a wide variety of learning styles. The functions available and a few of their collaborative synchronous e-learning uses are:

- A slide or file display that allows the instructor to show students PowerPoint slides or other files.

- A whiteboard to brainstorm a list of ideas

- Application sharing, so the instructor can do a software demonstration from one computer that can be seen by every attendee.

- Tool access, so the instructor can share the ability to use tools and functions of the online interface with students or other instructor.

- Peer-to-peer Chat, to get students to connect with other students.

- Instant feedback, to confirm the appropriateness of the pace and the content.

- Annotation, to focus students' attention on a specific area of the screen.

\section{A. Log-in with face recognition}

Using only a browser, students and presenters can attend their Synchronous e-Learning on the Web by face recognition log-in and face tracking to access learns the content and multimedia. 


\section{B. Slide or display file}

Instructor and Audience can use slides to help organize their content for presentation and to manage the flow of ideas. Bulleted lists, graphs, photographs, and screen captures help participants follow along. Often, by using this feature the instructor can also show sample documents created in Word, Flash, or HTML format. In fact, most products let you use the slides you already have, and they may support custom animations in PowerPoint. Another use of slides is similar to the advertising and trivia shown at movie theaters before the lights are turned down and the preview clips begin.

\section{Whiteboard}

With a whiteboard, instructors can encourage students to share ideas and comments through brainstorming, ask questions, and type their responses on the whiteboard. This promotes interaction, validates student input, and provides clarification for others who may not have heard the answers. The instructor can also use the whiteboard to sketch or annotate.

\section{Tool access and sharing}

The leader or leaders of the session control the images and tools that all online participants see. They can display files, annotate important points, and create quizzes slides. Students can contribute verbally, but cannot control the tools. You, or the training coordinator who sets up the session, can select the access level for each of the invitees so that two or more instructors can take turns delivering. There are also options that give all participants (almost) equal control.

\section{E. Peer-to-peer Chat}

Chat gives participants direct access to each other via text messaging, thus providing a forum for sidebar conversations and comments. Sessions where students work through a scenario and report their results to the group.

\section{F. Student-to-Instructor Chat}

Students are able to direct questions and ask for clarification without interrupting the flow of the class. Simply type their response back to the student.

\section{G. Instant feedback}

The comment I hear most from instructors about teaching online is that they miss being able to connect with students by observing behavior and asking Using instant feedback features, students can change an option on their screens to alert the instructor to slow down, speed up, or clarify.

\section{H. Annotation}

Create impact with annotation tools by drawing arrows to a particular object on the screen, circling or underlining words, or adding text on the fly. Participants can also use annotation tools in interactive exercises.

\section{Multimedia content}

Vary your instructional methods and engage student interest by showing AVI, Flash, or other action clips. Check your software product information for a list of supported file types. Users can use clips from Help files, materials, portions of asynchronous learning tools, or your own examples. Keep the clips short and highly relevant. Participants tend to surf away to something else if they lose interest.

\section{J. Live demonstrations}

This feature is useful in software training. Participants see how a software function as the instructor performs the actual clicks. When instructor design a live demonstration that may be lengthy, such as touring complex dialog boxes, include questions instructor can ask that will prompt students' verbal participation.

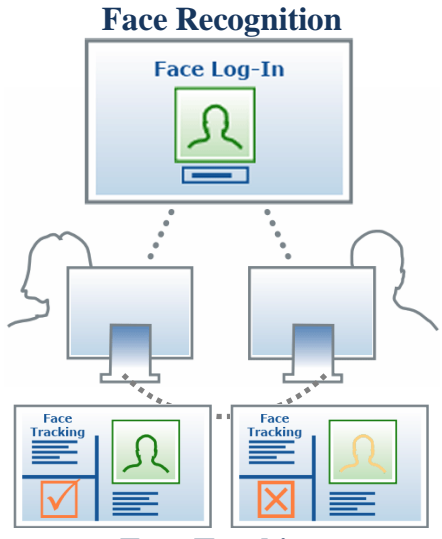

Face Tracking

(a) Face recognition log-in and face tracking.

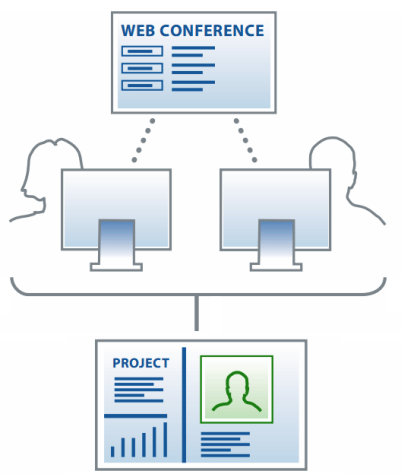

(c) Learners engage with one another to collaborate and share knowledge by asking questions, exchanging perspectives and experiences, and creatively expressing themselves.

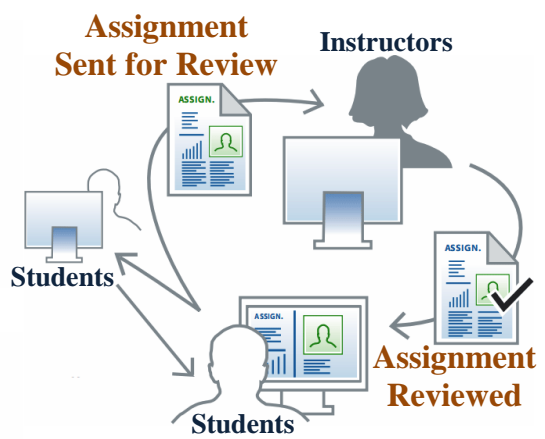

(d) A wide variety of multimedia, print, and communication resources help educators share new ideas and information with all members of the learning community, no matter where they are located, whenever they need it most.
Figure 2. Solutions of Intelligent Face Tracking for Collaborative Synchronous e-Learning

\section{$K$. Integrated telephony and VolP}

Users can handle the audio portion of the course that is the voices of the presenter and the participants with a simultaneous conference call. Voice over IP (VoIP) technology where voice is transferred over the Internet 
making use of the microphone and speakers on each user's PC. VoIP users may experience a choppy audio sound most frequently attributed to their Internet connection speed.

\section{Video integration}

Video integration allows participants and instructor to both see and hear each other on screen. If you want to see multiple participants, just change channels.

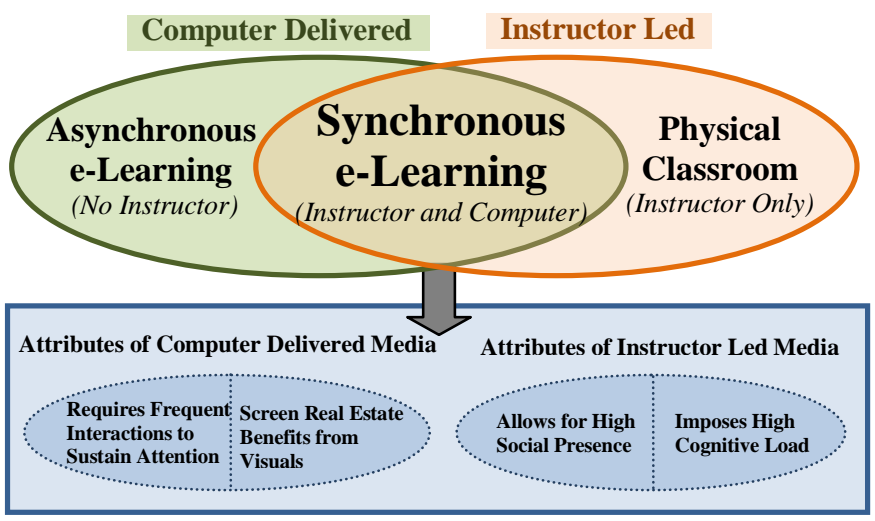

Figure 3. Computer Delivered and Instructor Led Learning Intersect

The research methodology of the e-Leanring P3 Development and Delivery Model consisted of two sections: Content Development and Content Delivery.

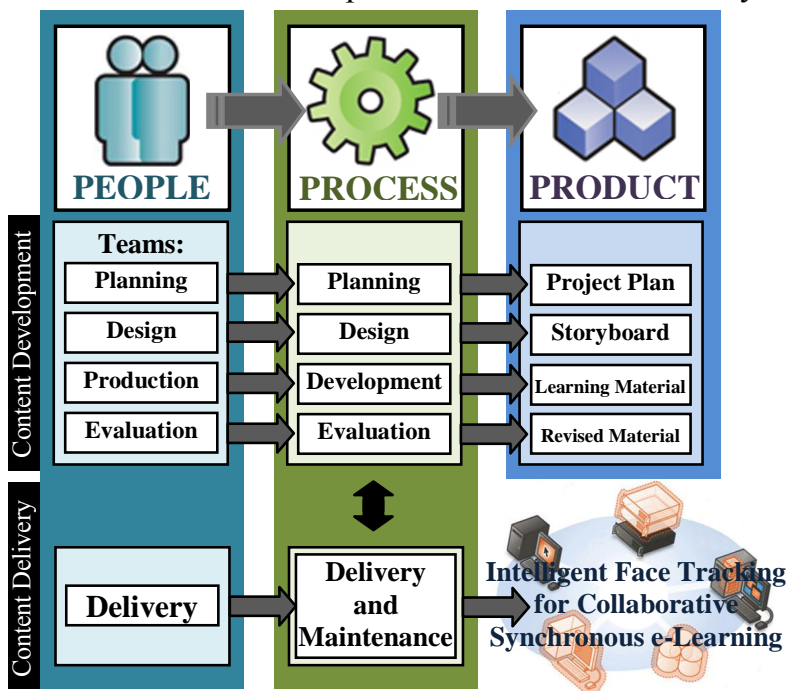

Figure 4. E-Leanring P3 Development and Delivery Model

\section{Challenges AND LimitATIONS TO COMSIDER}

While there are numerous advantages to adopting synchronous e-Learning, there are also challenges and limitations to consider. These range from the logistical to the pedagogical to the techno logical.

\section{A. Logistical}

Time zone differences are significant for live training, especially for global events. If users have a largely mobile workforce, determine whether synchronous attendance is the most appropriate method for reaching them. Typically you won't replace another training strategy completely; users may need to have resources capable of also providing faceto-face and asynchronous online methods.

\section{B. Pedagogical}

Synchronous e-Learning requires the resources and know-how for effective design. Existing face-to-face course designs will need to be repurposed for the more interactive requirements of the Collaborative synchronous e-learning. "Death by PowerPoint" will reduce learning effectiveness and create negative connotations among learners. Expect to invest in a program for training trainers on designing and developing use of these tools. Respect global cultural differences; identify and embrace how trainees respond variously to virtual synchronous approaches.

\section{Technological}

Bandwidth is crucial. Although some online synchronous tools can scale down for modem users, most require stable connections and high bandwidth. Consider also the firmwide impact on their network of multiple simultaneous users. Identify your audience. Will users need a Cross-platform, cross-browser solution? Coordinate any reconfiguration or restrictions on port, protocol, firewall, and file type policies with their IT representatives.

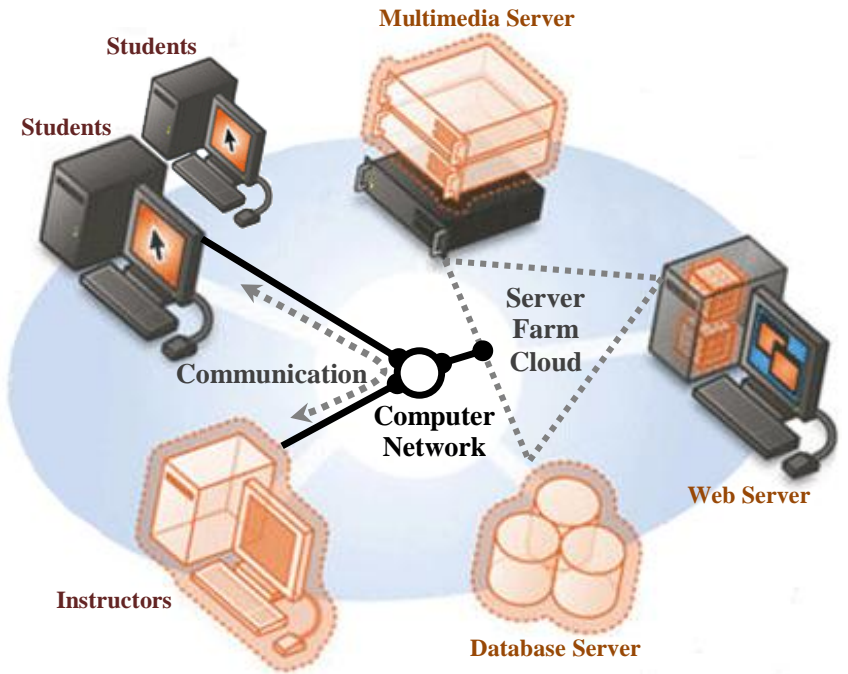

Figure 5. Infrastructure of Intelligent Face Tracking for Collaborative Synchronous e-Learning

\section{FACE RECOGNITION AND TRACKING}

Face recognition log-in and face tracking to access learns the content and multimedia, collaborative synchronous e-learning is live conferencing. As with eigenspace projection, training images are projected into a subspace. The test images are projected into the same subspace and identified using a measure similarity. The difference of recognition method is how the subspace is calculated which used projection of training images into a subspace. The test images projected into 
the same subspace and identified using a similarity measurement. The only difference is the method of calculating the subspace characterizing the face space. The face has the minimum distance with the test face image labeled with the identity of that image. The minimum distance can be Face Database of Testing Set Projection which used by Test Image Training Set Feature Vector (Feature Extraction) Feature Vectors Classifier (Euclidean Distance) Decision Making for Human Face Recognition calculated using the Euclidian distance method.

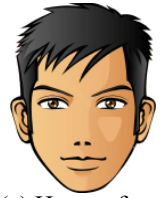

(a) Human face

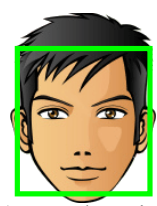

(b) Face detection

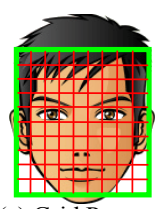

(c) Grid Pattern

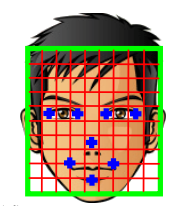

(d) T-Zone Pattern
Figure 6. Step of face recognition
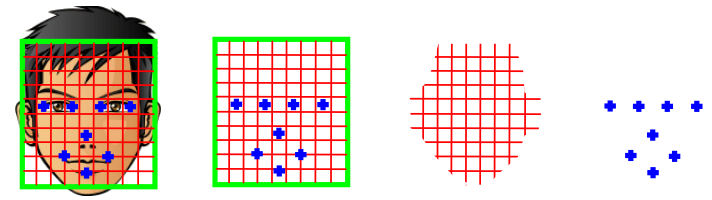

Figure 7. Point are transferred to a database as an algorithm of numbers

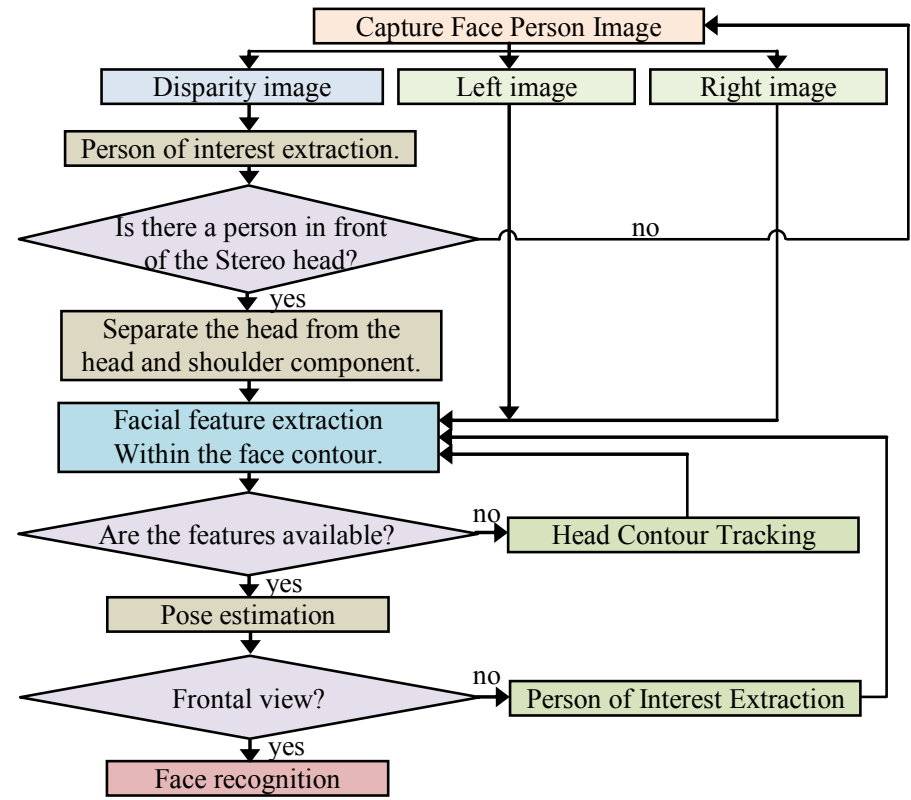

Figure 8. Flowchart of the face tracking algorithm

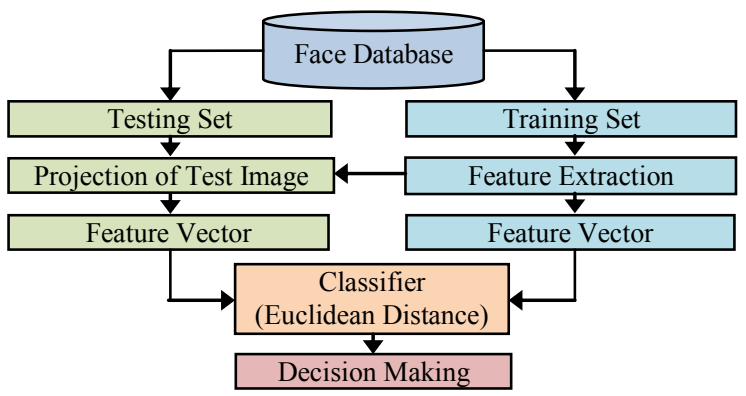

Figure 9. Approach for face recognition

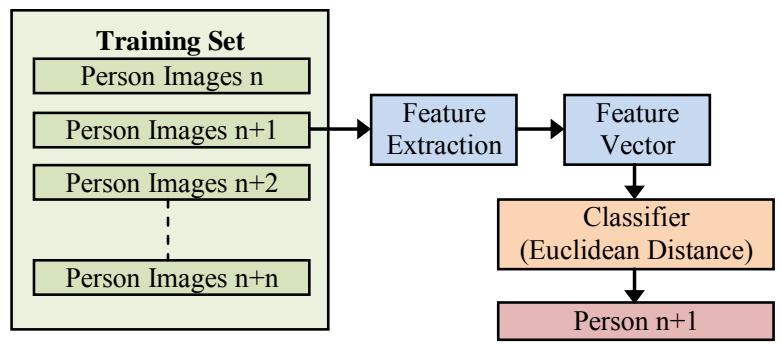

Figure 10. Training phase of face recognition

\section{CONCLUSION}

Building and delivering online events takes a lot of preparation and a few pairs of hands, but with practice, instructor can create excellent and effective learning experiences. Collaborative exercises can help get over the problem of a heterogeneous audience by letting the experts within student teams shine. But in general, the Intelligent Face Tracking for Collaborative Synchronous e-Learning has a hard time on its own handling a diverse audience and complex tasks that require contemplation. This is why users may at times want to turn to what is done to distributing content across or through diverse media choosing the best medium for each topic or learning objective.

\section{REFERENCES}

[1] Mihaela Sabin , "A Collaborative and Experiential Learning Model Powered by Real-World Projects" SIGITE'08, pp.157-164, October 16-18, 2008, Cincinnati, Ohio, USA.

[2] Gorka, S., Miller, J.R., and Howe, B.J. 2007. Developing Realistic Capstone Projects in Conjunction with Industry. In Proceedings of the SIGITE Conference on Information Technology Education (Destin, FL, USA., October 2007).

[3] ROBERT M. AIKEN, MARIE-NOELLE BESSAGNET, JUDITH ISRAEL, "Interaction and Collaboration Using an Intelligent Collaborative Learning Environment" Education and Information Technologies 10:1/2, 65-80, 2005 .

[4] Suthers, D. D., Erdosne-Toth, E., and Weiner, A. (1997) 'An Integrated Approach to Implementing Collaborative Inquiry in the Classroom Retrieved'

[5] Levialdi, S., Malizia, A.: Modeling Collaborative Interactions in a network of Digital Libraries. In: Proceedings of the I International Conference on MultidisciplinaryInformation Sciences and Technologies (INSCIT 2006), Merida (Spain), vol. I, pp.181-185 (October 2006)

[6] Christensen, R., Garvin, D., Sweet, A. (1991). Education for Judgment. Boston. Harvard Business School.

[7] T. Hern'n Sag·stegui Ch., JosÈ E. Labra G., Juan M. Cueva L., JosÈ M. Morales G., Marl̀a E. Alva O., Eduardo ValdÈs, and Cecilia Garcla, "A Collaborative E-learning Component for the IDEFIX Project' ICWE 2003, LNCS 2722, pp. 116ñ119, 2003.

[8] G. Gauthier, C. Frasson, K. VanLehn (Eds.) "How Can We Form Effective Collaborative Learning Groups?” ITS 2000, LNCS 1839 , pp. 282-291, 2000.

[9] Amy Soller, Bradley Goodman, Frank Linton, and Robert Gaimari, "Promoting Effective Peer Interaction in an Intelligent Collaborative Learning System" B.P. Goettl et al. (Eds.): ITS '98, LNCS 1452, pp. 186-195, 1998.

[10] SooHwan Kim, Hyeoncheol Kim, and SeonKwan Han, "The Study on Visualization Systems for Computer-Supported Collaborative Learning” Z. Pan et al. (Eds.): Edutainment 2008, LNCS 5093, pp. $107-113,2008$

\section{Creative Commons Attribution License 4.0 (Attribution 4.0 International, CC BY 4.0)}

This article is published under the terms of the Creative Commons Attribution License 4.0

https://creativecommons.org/licenses/by/4.0/deed.en_US 